\title{
Regional variation in larval retention and dispersal drives recruitment patterns in a temperate reef fish
}

\author{
Stephen E. Swearer ${ }^{1, *}$, Jeffrey S. Shima ${ }^{2}$ \\ ${ }^{1}$ Department of Zoology, University of Melbourne, Victoria 3010, Australia \\ ${ }^{2}$ School of Biological Sciences and Coastal Ecology Lab, Victoria University of Wellington, Wellington 6140, New Zealand
}

\begin{abstract}
Although there is wide appreciation for the influence of variable larval transport on recruitment, few studies have investigated the relationship between recruitment intensity and the origin(s) of recruits. We evaluate this relationship for the common triplefin Forsterygion lapillum in Wellington Harbour (a semi-enclosed bay) and the adjacent open coast of North Island, New Zealand. As the harbour is productive, with many F. lapillum adults, we predicted the harbour would be an important source of recruitment for both regions. We estimated larval origins and dispersal histories using embryonic and larval otolith chemistry, respectively, with differences in otolith elemental composition consistent with birth and/or development in either harbour or open ocean waters. In the harbour, recruitment was greatest when locally spawned larvae were retained. Although large recruitment pulses to the open coast were comprised mostly of larvae originating from the open coast, $72 \%$ of all recruits to the south coast were actually spawned in the harbour. Dispersal of larvae from the harbour was frequent, but in low numbers, and was unrelated to opportunities for transport from the harbour. Given recent evidence for differences in larval growth between regions, we suggest that (1) faster larval growth combined with nearshore larval distributions result in high recruitment to the harbour and moderate, but demographically important, dispersal from the harbour to the open coast. In contrast, we suggest that (2) the combination of strong tidal currents in Cook Strait and slower larval growth result in lower recruitment and greater transport of larvae among open coast populations. The mechanisms that underlie such contextdependent dispersal have important implications for patterns of connectivity.
\end{abstract}

KEY WORDS: Recruitment variability · Larval dispersal - Natal origin · Self-recruitment · Connectivity · Member-vagrant hypothesis $\cdot$ Drift-retention dichotomy $\cdot$ Reef fish

\section{INTRODUCTION}

Marine species typically have planktonic larvae capable of broad dispersal and their return to adult populations is often variable, resulting in substantial fluctuations in population size (Caley et al. 1996). Despite considerable research, particularly on the roles of variable larval production and mortality (see Leggett \& Frank 2008), there is still extensive debate over the causes of recruitment variation. While larval transport has long been appreciated as another important driver of recruitment variability (Hjort 1914, Thorson 1950), in recent decades there has been renewed interest, particularly in relation to the relative impor- tance of retention and dispersal to recruitment (e.g. the member-vagrant hypothesis, Sinclair 1988; the driftretention dichotomy, Campana et al. 1989). In some instances, local recruitment rates may be enhanced when physical transport processes facilitate larval delivery to neighboring populations (a highly connected metapopulation), whereas in other instances, recruitment rates may be enhanced when larvae are retained near the natal population (a self-recruiting local population). Despite reasonable evidence in support of the member-vagrant hypothesis (see Leggett \& Frank 2008), the relationship between recruitment intensity and the origin(s) of recruits is still poorly known for most species. 
In large part, progress in this area has been hindered by the logistical difficulties of tracking larvae in the pelagic environment (Swearer et al. 2002). One method of indirectly determining the origins of recruiting larvae is the use of natural environmental markers (e.g. Swearer et al. 1999, Patterson \& Swearer 2007). Importantly, this approach has been used to investigate how spatio-temporal variability in larval transport processes can result in differences in the relative importance of dispersal and retention as mechanisms of population replenishment. For example, Gaines \& Bertness (1992) used differences in the size of competent larvae of the barnacle Semibalanus balanoides to distinguish between larvae that were spawned and developed within Narragansett Bay, Rhode Island, USA, and larvae that developed in coastal waters outside the bay. Size-frequency distributions of settlers within Narragansett Bay suggested that populations were primarily locally replenished whereas open coast populations received a mixture of larval sources, with bay populations contributing as much as $50 \%$ of the recruitment in years when larvae were flushed out of the bay.

The physico-chemical properties of ambient water recorded in calcified structures such as the otoliths of larval fish can also be used as natural tags of larval origin and dispersal history (Thorrold \& Swearer 2009). Using this approach, Swearer et al. (1999) determined that the relative importance of local retention and dispersal to recruitment of bluehead wrasse Thalassoma bifasciatum on St. Croix, US Virgin Islands, varied spatially, with high recruitment to leeward reefs occurring when larvae were locally retained and high recruitment to windward reefs occurring when larvae were dispersing from up-current source populations. Together, these studies suggest that natural tags can be a useful tool for investigating spatio-temporal variability in the sources of recruitment, particularly over the likely spatial scales of retention and dispersal in most marine species and systems.

Such variation in the mechanisms of replenishment in marine systems highlights the importance and relevance of metapopulation frameworks for understanding marine population dynamics (Swearer et al. 2002, Kritzer \& Sale 2004). Within a metapopulation framework, different local populations or regions of the metapopulation may be self-recruiting (Swearer et al. 2002) or dependent upon recruits from different sources (Cowen et al. 2006) to varying degrees. Therefore, patterns of recruitment may be shaped by how physical transport processes influence dispersal and retention across the metapopulation (Cowen \& Sponaugle 2009). Although a growing number of studies have shown that self-recruitment can be an important mechanism for replenishment (e.g. Jones et al.
1999, Swearer et al. 1999, Almany et al. 2007), there are surprisingly few studies that have investigated the importance of larval origins and larval dispersal histories as drivers of variation in recruitment.

Here, we investigate patterns of recruitment variability in a common reef fish and then utilize otolith chemistry to assess whether differences in the origins and dispersal histories of recruits are capable of predicting this variation. Our results suggest that the relationships between recruitment and recruit origins and dispersal histories differ between regions and thus have important implications for population persistence in a marine metapopulation.

\section{MATERIALS AND METHODS}

Study system. We investigated how the origins and dispersal histories of recruits influence the magnitude of recruitment of the common triplefin Forsterygion lapillum, a small and abundant fish species on shallow rocky reefs and in tide pools throughout New Zealand (Clements 2003, Feary \& Clements 2006, Wellenreuther et al. 2007). Females spawn benthic egg clutches that are cared for by territorial males for 2 wk until hatching (Thompson 1979, Francis 2001, authors' unpubl. data). Larvae develop in the pelagic environment for 50 d (Shima \& Swearer 2009a) before settling to fronds of macroalgae (McDermott \& Shima 2006).

We sampled recruitment of Forsterygion lapillum from 3 locations within each of 2 regions: Wellington Harbour and the adjacent south coast of North Island, New Zealand (see Shima \& Swearer 2009b for a map of the study location). Wellington Harbour is a semienclosed bay that receives significant freshwater inputs from the Hutt River (average flow for $2004=3 \times$ $10^{6} \mathrm{~m}^{3} \mathrm{~d}^{-1}$, peak flow $=92 \times 10^{6} \mathrm{~m}^{3} \mathrm{~d}^{-1}$ on 16 February 2004; Wellington Regional Council). Tidal exchange between the harbour and open coast is limited ( 4.5\% of the total harbour volume per tidal cycle; Maxwell 1956). Nutrient inputs into Wellington Harbour result in greater concentrations of plankton relative to open coast waters (Gardner 2000).

Quantifying variation in recruitment. We used standardised recruit collectors (i.e. artificial substrates comprised of plastic mesh bundles, described in Ammann 2004; see Shima \& Swearer 2009a,b for details of methods) to sample recently settled Forsterygion lapillum at approximately weekly intervals between December 2003 and March 2004 (spanning the period of peak recruitment for this species, authors' unpubl. data). Three replicate collectors were deployed at each site, separated from one another by at least $20 \mathrm{~m}$. Three sites (Kaiwharawhara, Eastbourne, and Shelly 
Bay) were located within Wellington Harbour and another 3 sites (Island Bay, Princess Bay, and Moa Point) were located along the adjacent south coast. All F. lapillum recruits were collected during each of 8 sampling events (roughly weekly intervals) with recruitment rates expressed as recruits $\mathrm{d}^{-1}$ collector $^{-1}$ (no. of recruits on collector per no. of days between sampling dates). Estimates of recruitment were averaged across collectors to yield one measure of daily recruitment per site per sampling event.

For this study, we were primarily interested in testing for differences in the magnitudes and timing of recruitment that might be indicative of regional differences in the sources of larval inputs. Hence, we used a 2-factor, fully crossed ANOVA (JMP v7.0.2) model (region and date treated as fixed factors), with mean daily recruitment at the level of site used as replicates, resulting in a total of 48 replicate observations (8 survey periods $\times 3$ sites per region $\times 2$ regions). In order to conform to assumptions of ANOVA, we analysed a 4 th root transformation of daily recruitment because our data were strongly right-skewed.

Environmental correlates of variation in recruitment. As adult Forsterygion lapillum are considerably more abundant in Wellington Harbour than the adjacent south coast (authors' unpubl. data), we hypothesized that temporal variation in the degree of water retention versus flushing of the harbour could result in differences in the timing and magnitude of recruitment to both regions if the harbour is the primary source of recruits (sensu Gaines \& Bertness 1992). To test this hypothesis, we compared the recruitment time series from both regions to 3 environmental proxy measures for flushing rates of the harbour: discharge of water from Hutt River, the largest catchment that drains into the harbour; the duration and intensity of northerly wind events, which would push surface waters out of the harbour; and daily minimum sea-surface height as a measure of periods of strong tidal/pressure-driven flow out of the harbour. If harbour flushing/retention dynamics are relevant, we predicted that recruitment to the harbour and south coast would be negatively correlated to each other, and periods of increased recruitment to the south coast would occur during periods of increased flushing. We tested this prediction by comparing time series visually and testing for relationships among recruitment and weekly averages of the 3 environmental proxy measures using Pearson's correlation. We did not perform further analysis of these data because the length of our recruitment time series and the frequency of recruit sampling was insufficient for robust detection of relationships (or lack thereof) using other approaches. All environmental data were provided by the Wellington Regional Council (www. gw.govt.nz/our-environment/).
Reconstructing larval dispersal history and source population identity. We used chemical signatures recorded within the sagittal otolith of recently settled Forsterygion lapillum cleared from the collectors to characterize and discriminate among putative 'source populations' and 'pelagic larval dispersal histories'. Incorporation of a range of trace elements into otoliths is often a function of the chemical and/or physical properties of the surrounding seawater (Campana 1999, Swearer et al. 1999, 2002). The resultant microchemical signature recorded within the embryonic otolith (i.e. for F. lapillum, the region of the otolith formed at the natal site, prior to hatching) therefore comprises an 'environmental fingerprint' of a putative source population (sensu Barbee \& Swearer 2007). Similarly, microchemical signatures recorded across the pelagic larval growth axis characterize the larval environmental history experienced by recently settled F. lapillum.

To reconstruct larval dispersal history and source population identity, sagittal otoliths from a subsample of 321 fish (a random sample of up to 10 recruits per site per collection date) were cleaned, mounted, and polished to within $20 \mu \mathrm{m}$ of the core following the methods of Patterson \& Swearer (2007), Barbee \& Swearer (2007), and Shima \& Swearer (2009a). Quantification of the concentrations (relative to $\mathrm{Ca}$, the internal standard) of the elements (with detection limits in $\mu \mathrm{mol} \mathrm{mol}{ }^{-1} \mathrm{Ca}$ in parentheses) ${ }^{7} \mathrm{Li}(5.19),{ }^{11} \mathrm{~B}$ (21.4), ${ }^{24} \mathrm{Mg}$ (13.5), ${ }^{31} \mathrm{P}$ (60.2), ${ }^{34} \mathrm{~S}$ (177), ${ }^{55} \mathrm{Mn}$ (2.96), ${ }^{63} \mathrm{Cu}(0.960),{ }^{66} \mathrm{Zn}(2.29),{ }^{88} \mathrm{Sr}(0.349),{ }^{138} \mathrm{Ba}(0.0342)$ and ${ }^{208} \mathrm{~Pb}(0.0357)$ in recruit otoliths was performed on a Varian inductively-coupled plasma mass spectrometer (ICP-MS) fitted with a HelEx (Laurin Technic and the Australian National University) laser ablation (LA) system constructed around a Compex 110 (Lamda Physik) excimer laser operating at $193 \mathrm{~nm}$ (see Eggins et al. 1998 for a description of the LA system and Barbee \& Swearer 2007 for details of LA-ICP-MS methods).

Each otolith was analysed in 2 ways: using a stationary laser with a $19 \mu \mathrm{m}$ spot to drill down through the otolith core (to characterize putative source populations), and using a moving laser (scan rate $=2.5$ scans $\mathrm{s}^{-1}$; stage movement rate $=3 \mu \mathrm{m} \mathrm{s}^{-1}$ ) with a $5 \times 80 \mu \mathrm{m}$ rectangular spot, resulting in a high resolution 'transect' ( $80 \mu \mathrm{m}$ wide) across the postrostral growth axis of the otolith (to characterize larval dispersal histories). For both the source population and dispersal history analyses, the time series were truncated to only include analyses of pre-hatch and pre-settlement otolith material, respectively (see Shima \& Swearer 2009a for details).

We used a series of multivariate statistical approaches to first characterize the time series data and then subsequently cluster fish with similar chemical signa- 
tures into a discrete number of groups with respect to (1) otolith core microchemistry (i.e. putative source populations); and (2) larval otolith transect microchemistry (i.e. pelagic larval dispersal histories). To summarize, we first characterized the dynamics of each of the 11 elemental ratio time series from both the core and transect analyses for each recruit using a set of 13 univariate descriptors, or 'extracted features' using $\mathrm{R}$ (R Core Development Team, http://cran.r-project.org). The 13 univariate descriptors consisted of a serial correlation function, a non-linear function, a skewness function, a kurtosis function, a Hurst function, a Lyapunov function, a frequency function, a trend function, a seasonal function, and trend and seasonally adjusted (TSA) functions for serial correlation, nonlinearity, skewness, and kurtosis (for detailed descriptions and interpretations of each extracted feature see Wang et al. 2006, Shima \& Swearer 2009a).

The resultant 143 descriptors were then standardized (mean $=0, \mathrm{SD}=1$ ) and used in a hierarchical cluster analysis (CLUSTER procedure, SAS v9.1) to determine the number of clusters by evaluating consensus among the cubic clustering criterion, pseudo F statistic and pseudo $t^{2}$ (SAS Institute 1999). Cluster identities were subsequently determined using a $k$-means (unconstrained) clustering algorithm (FASTCLUS procedure, SAS v9.1), which assigns fish to clusters independently of site or time of collection. This approach resulted in the following groupings: (1) 2 discrete putative source populations (based upon otolith core features); and (2) 2 discrete putative larval dispersal histories (based upon larval otolith transect features) (see Shima \& Swearer 2009a). Incorporation of many of the elements quantified in Forsterygion lapillum otoliths is influenced by temperature and freshwater discharge, both of which vary consistently between Wellington Harbour and Cook Strait (authors' unpubl. data). These environmental gradients support our conclusion that cluster identities are consistent with harbour and open coast origins (based on otolith core chemistry) and harbour and open coast development (based on larval otolith chemistry) (Shima \& Swearer 2009a).

We then performed a discriminant function analysis (CANDISC procedure, SAS v9.1) using the cluster groupings to generate canonical factor (CF) scores for each fish based on their source cluster, i.e. mean (min.max.) CF1 scores: harbour recruits $=0.003(-0.992-$ 1.694), open coast recruits $=0.420(-1.799-2.885)$, and dispersal history cluster, i.e. mean (min.-max.) CF1 scores: harbour recruits $=-0.142(-1.842-2.082)$, open coast recruits $=0.549(-3.653-3.751)$. The purpose of this analysis was to generate univariate scalar measures of each larva's source cluster and dispersal history cluster that could be averaged within cohorts to compare to the magnitude of recruitment (sensu
Swearer et al. 1999). Discrimination between both source and dispersal clusters was very high, with $98.5 \%$ reclassification success to source population cluster and $97.8 \%$ to dispersal history cluster.

Relationships between recruitment and larval origin and dispersal history. We used multiple linear regression (JMP v7.0.2) to evaluate the relationship between recruitment intensity (4th root transformed daily recruitment rate) and larval origin (CF1 scores from cluster analysis of otolith cores features) and larval dispersal history (CF1 scores from cluster analysis of otolith transect features). No transformations of the CF1 scores were required to meet model assumptions based on residual plots. We evaluated these relationships separately for each region (using site averages for each census period as replicates) because we expected a priori that the origins and dispersal histories of larvae would vary between regions (Shima \& Swearer 2009a,b). Thus, for this analysis, we had 3 sites per region that were each sampled 8 times, resulting in up to 24 replicate observations in each region. Due to periods of no recruitment or insufficient numbers of recruits for otolith analysis, the total number of replicates for the harbour and open coast regression models were 23 and 18, respectively.

\section{RESULTS}

Recruitment of Forsterygion lapillum varied between regions $\left(F_{1,32}=26.174 ; \mathrm{p}<0.0001\right)$ but not among sample dates $\left(F_{7,32}=1.384 ; \mathrm{p}=0.246\right)$ in our study, and this regional difference was consistent through time $\left(F_{7,32}=\right.$ $0.251 ; \mathrm{p}=0.968$, Fig. 1). On average, recruitment of F. lapillum in the harbour was more than double that observed on the open coast, and there were no time periods when recruitment was elevated on the open coast and depressed in the harbour as would be predicted if the flushing of harbour developing larvae was the cause of large recruitment events to the open coast. In fact, recruitment was positively correlated between regions $(\mathrm{r}=$ 0.693), although this relationship was marginally nonsignificant ( $p=0.057$ ). This result is consistent with the lack of any observable relationship between environmental proxies of harbour flushing and recruitment (Fig. 1). Although there were periods of large river discharge, predominantly northerly winds and low minimum water levels, this variation did not translate into any corresponding changes in recruitment to the harbour or the open coast (correlations between weekly averages of all environmental proxies and recruitment to the harbour and open coast: $r=-0.07$ to $0.38, p>0.35$ ), either at the time of settlement or during the $50 \mathrm{~d}$ prior to settlement (the average planktonic larval period of F. lapillum; Shima \& Swearer 2009b). 

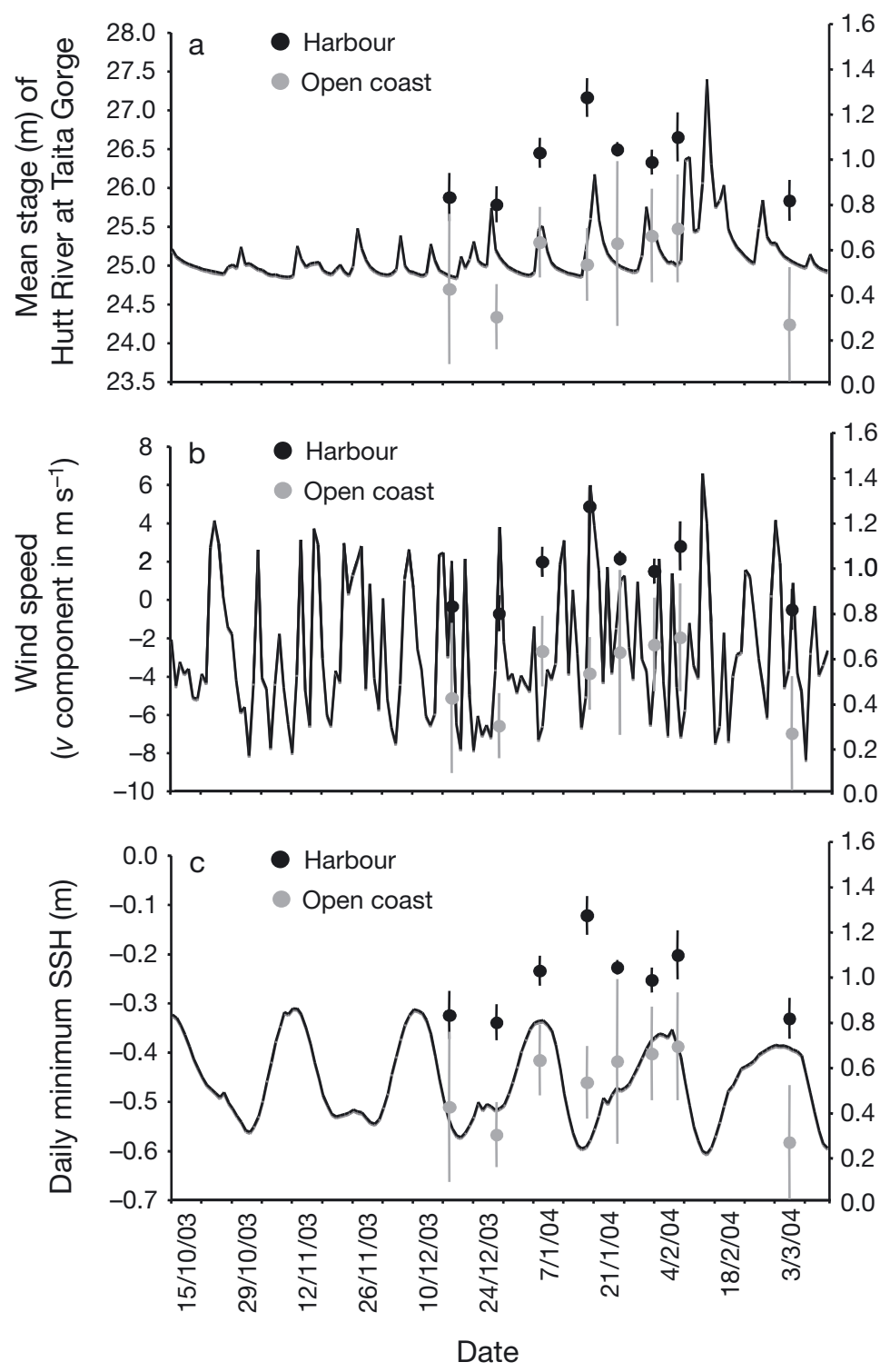

Fig. 1. Forsterygion lapillum. Recruitment patterns (circles, mean $\pm 1 \mathrm{SE}$ ) of the common triplefin to Wellington Harbour (harbour) and the adjacent south coast of North Island, New Zealand (open coast), in relation to the following environmental proxy measures (lines) of Harbour flushing during the time of larval development: (a) Hutt River discharge; (b) northerly (negative velocity) wind events; and (c) periods of strong tidal/pressure-driven flushing (protracted low minimum sea surface heights, SSH). Dates: dd/mm/yy

Recruitment of Forsterygion lapillum to the harbour was significantly influenced by the interaction between larval origin and larval dispersal history (Table 1). In general, recruitment to the harbour was high when the majority of settlers were sourced from the harbour (high larval origin CF1 scores) and had developed in the harbour (low dispersal history CF1 scores, Fig. 2a). In addition, most small recruitment events $(\leq 1)$ were comprised predominantly of larvae that were sourced from the harbour but that had spent much of their larval development in more open ocean environments (i.e. located in the upper right-hand quadrant of Fig. 2a). Overall, $72 \%$ of replenishment within the harbour was a result of self-recruitment, with a further $13 \%$ resulting from the retention of opencoast larvae within the harbour. Only $15 \%$ of recruitment to the harbour resulted from the transport of southcoast larvae that spent most of their development in oceanic waters.

In contrast, recruitment of Forsterygion lapillum to the south coast was only affected by larval origin (Table 1). Recruitment of $F$. lapillum to the south coast was high $(>0.9)$ when recruits were sourced from the open coast (low CF1 scores, Fig. 2b). However, most recruitment events to the south coast were small $(<0.4)$. During these small recruitment events, the majority of settlers had source population signatures indicative of harbour origins and dispersal histories indicative of open coast development. Overall, $71 \%$ of recruits to the south coast originated from the harbour and $65 \%$ of these recruits developed primarily in open coast waters.

\section{DISCUSSION}

Regional differences in recruitment of Forsterygion lapillum are shaped by differences in the importance of retention and dispersal. In Wellington Harbour, the majority of recruits (72\%) were spawned in the harbour and recruitment was highest when locally spawned larvae had been retained within the harbour during development. On the open coast, the majority of recruits $(71 \%)$ originated from the harbour. These dispersal events were frequent and relatively small whereas large recruitment events comprised primarily of larvae spawned on the open coast. Thus, recruitment within the harbour is primarily a result of local larval production and retention whereas recruitment to the south coast is a function of frequent dispersal from the harbour and infrequent but significant pulses of recruitment of larvae originating from open coast populations.

The differences among regions in the importance of dispersal and retention are likely to be driven, in part, 
Table 1. Forsterygion lapillum. Effects of larval origin and dispersal history on variation in recruitment intensity of the common triplefin. Recruitment was sampled on 8 dates at triplicate sites within 2 regions, Wellington Harbour and the adjacent south coast of North Island, New Zealand (open coast). Due to insufficient or total lack of recruitment on sites for certain periods, a total of 23 and 18 (site $\times$ time) out of 24 replicates resulted for the harbour and south coast, respectively. Larval origin and dispersal history covariates were based on the mean canonical factor (CF) scores of recruits that settled to a site on each sampling date. $\mathrm{CF}$ scores were calculated for each recruit based on discriminant function analyses of larval origin and dispersal history groupings from a $k$-means cluster analysis (see 'Materials and methods' for details). ${ }^{*} \mathrm{p}<0.05$

\begin{tabular}{|llrccc|}
\hline Region & Source & df & MS & $F$ & $\mathrm{p}$ \\
\hline Harbour & Origin & 1 & 0.003 & 0.119 & 0.734 \\
& Dispersal history & 1 & 0.030 & 1.015 & 0.326 \\
& Origin $\times$ Dispersal history & 1 & 0.148 & 5.081 & $0.036^{*}$ \\
& Error & 19 & 0.291 & & \\
Open coast & 1 & 0.530 & 7.550 & $0.016^{*}$ \\
& Origin & 1 & 0.041 & 0.582 & 0.458 \\
& Dispersal history & 1 & 0.164 & 2.340 & 0.148 \\
& Origin $\times$ Dispersal history & 14 & 0.070 & & \\
& Error & & & &
\end{tabular}
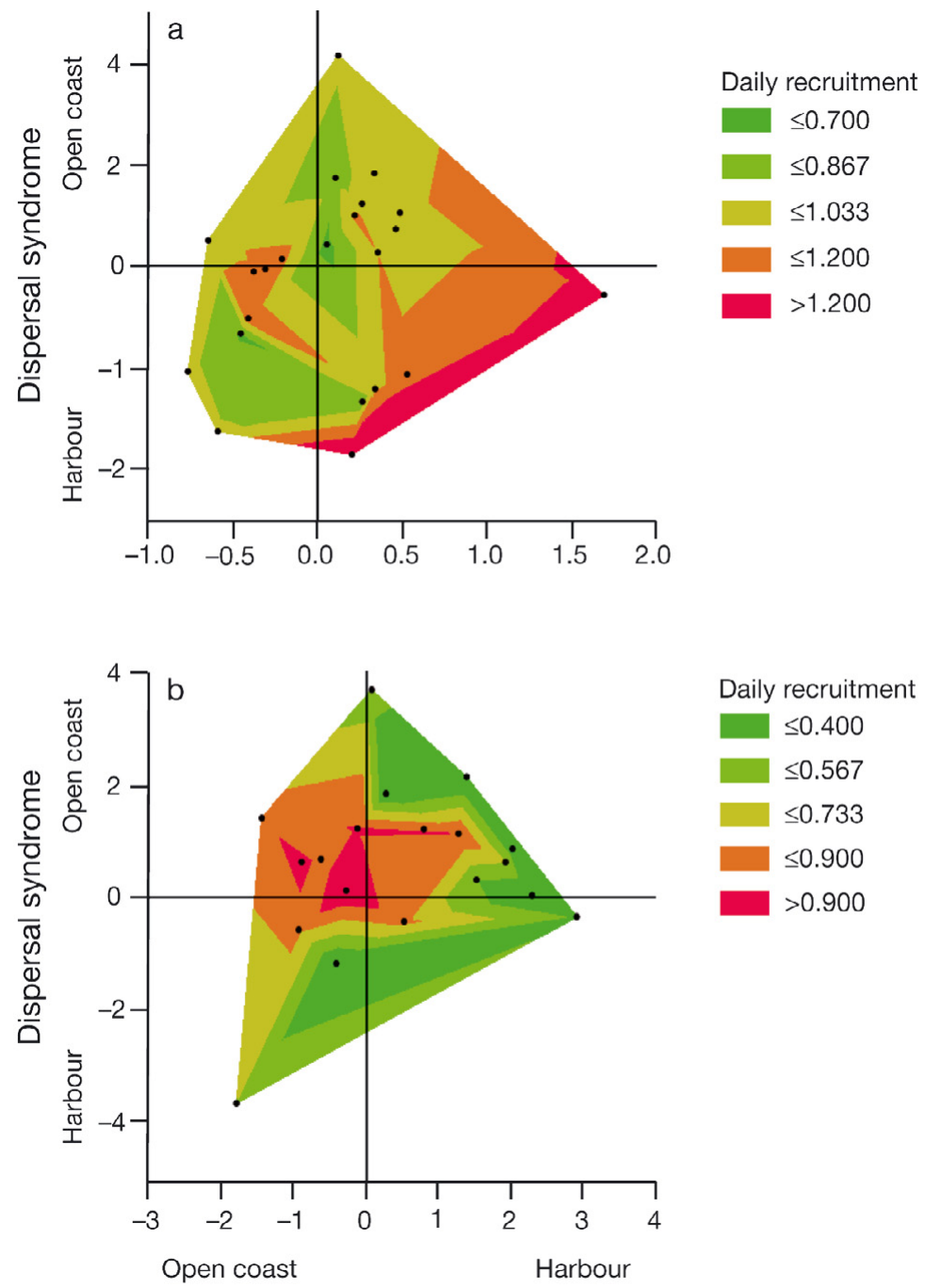

Daily recruitment

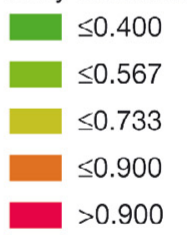

Source syndrome by regional differences in hydrodynamics. All developmental stages of triplefin larvae are typically found very nearshore (Kingsford 1988, Borges et al. 2007) and thus may not disperse far. Relative to the open coast, Wellington Harbour is characterised by weaker currents and limited tidal exchange, and larvae residing in these nearshore waters may be less prone to physical transport out of the local region. In contrast, larvae that develop on the open coast may frequently encounter the oceanic swells and strong tidal currents of Cook Strait. Interestingly, another study (Hickford \& Schiel 2003) conducted along an exposed coast of the South Island of New Zealand recorded triplefin larvae in highest densities far from shore: a likely outcome of larval development in a strongly advective environment. The apparent disparity in larval triplefin distributions recorded in relatively sheltered settings (Kingsford 1988, Borges et al. 2007) versus more exposed environments (Hickford \& Schiel 2003) is consistent with our findings based on otolith chemistry; both suggest dispersal patterns may be context dependent.

This conclusion is further corroborated by some of our previous research

Fig. 2. Forsterygion lapillum. Effects of larval origins (source syndrome) and dispersal histories (dispersal syndrome) on variation in recruitment of the common triplefin to (a) Wellington Harbour (harbour) and (b) the adjacent south coast (open coast) of North Island, New Zealand. Increasing source syndrome (canonical factor 1, CF1) values indicate a greater proportion of harbouroriginating larvae whereas increasing dispersal syndrome (CF1) values indicate a greater proportion of south coast-developing larvae. Intersecting lines: mean CF1 scores. Contour colours shows: magnitude of each recruitment event (black circles), with equal contour intervals between recruitment events. Coordinates of black circles show CF scores of recruits that comprise each recruitment event. Thus, high recruitment events in the harbour were dominated by larvae that originated and developed in the harbour (lower right-hand quadrant) whereas high recruitment events in the open coast were dominated by larvae that originated from open ocean waters along the south coast (left quadrants) 
on regional differences in recruitment in response to differences in larval condition. In Wellington Harbour, Forsterygion lapillum larvae settle at a younger age and in better condition relative to larvae on the open coast (Shima \& Swearer 2009b). Compared to the open coast, the harbour is nutrient enriched and supports higher standing stocks of plankton (Helson et al. 2007) and is therefore likely to be a more developmentally favourable environment. In contrast, the adjacent open coast has low abundance and diversity of benthic filterfeeding invertebrates (Gardner 2000) on rocky shores, which is suggestive of limited standing stocks of planktonic food resources for larvae developing in Cook Strait. Consequently, the positive correlation between recruitment intensity and larval condition further suggests the harbour is primarily self-recruiting (Shima \& Swearer 2009b). Along the open coast, larval condition was negatively correlated with recruitment. This result further supports the conclusion that high recruitment events to the open coast are comprised primarily of larvae spawned in open coast waters, as they would have dispersed primarily through poor quality (e.g. food depleted) environments and therefore would have arrived in poorer condition (Shima \& Swearer 2009b).

Taken together, the combination of high adult abundance and the favourable environmental conditions for larval growth and retention result in high selfrecruitment in the harbour. These same characteristics contribute to the harbour's importance as a regular source of recruits to the open coast. The importance of harbour-sourced recruits to the persistence of triplefin populations on the open coast may even be greater, as recruits from the open coast experience higher mortality due to their poor condition (Shima \& Swearer 2010). Such selective mortality can have important consequences to our understanding of marine population dynamics if initial patterns of dispersal and connectivity are modified prior to reproductive maturity (e.g. Hamilton et al. 2008). Furthermore, given that most of the recruits from open coast populations settled en masse during a few events suggests that densitydependent mortality may further reduce the contribution of open coast larvae to population persistence. Collectively, these findings suggest that open coast populations of triplefins may effectively be sinks, only persisting in the presence of immigration of larvae from the harbour. Further research in this system is needed to confirm whether source-sink dynamics are an important component of metapopulations in this species.

Our results are broadly similar to other studies that have investigated the role of larval transport as a driver of variation in recruitment. Similar to Gaines \& Bertness (1992), we found that a coastal bay was an important source of recruits to open coast populations, and that recruitment within the bay was primarily due to local retention. In contrast, however, we found no evidence for a role of bay flushing on larval dispersal to open coast populations. Although our time series was too short to provide a definitive test, the flushing events during our study were comparatively small, and triplefin larvae are likely to have moderately strong behavioural control over their dispersal (Leis 2006). As dispersal of larvae from the harbour to the south coast occurred consistently throughout the recruitment season, we suggest that these larvae may be in poorer condition and therefore may have reduced capacity to remain within the harbour regardless of the strength of harbour flushing.

In general, the processes which appear to be operating in this system seem concordant with the membervagrant hypothesis (Sinclair 1988). Retention in the harbour leads to greater 'membership', or closure of the life cycle; thus, there is positive feedback between increasing adult abundance and recruitment. Along the open coast, variable transport may play a greater role in shaping the numbers of recruits, where the accumulation of 'vagrant' individuals may more strongly contribute to large recruitment events. Thus, fundamentally different processes appear to shape recruitment variability over relatively small spatial scales. Indeed, the descriptors that have been used to describe these apparently different processes (e.g. member-vagrant hypothesis or the drift-retention dichotomy) emphasise a dichotomous set of alternatives. We suggest that these are merely the extremes along a continuum of dispersal patterns that can be described more inclusively by dispersal kernels (i.e. the distribution of dispersal distances from a source population). Within a dispersal kernel framework, larvae produced from different regions may have differently shaped dispersal kernels (e.g. Shima et al. 2010). For triplefin larvae produced within Wellington Harbour, the large majority of individuals may have short dispersal distances as they are retained within the harbour, whereas a minority of larvae, potentially in poorer condition (Shima \& Swearer 2010), may travel greater distances and recruit to other populations. In contrast, a higher proportion of larvae produced along the open coast may disperse widely, and this would be characterised by a more platykurtic dispersal kernel. Variation among differently shaped dispersal kernels and their patterns of overlap in space and time will have important consequences for local recruitment dynamics and patterns of dispersal and connectivity in a larger metapopulation.

Acknowledgements. This research was funded by 2 Marsden grants from the Royal Society of New Zealand (2003-04 to J.S. and S.S.; and 2007-09 to J.S., S.S., and S. Chiswell). Field logistic support was provided by the Victoria University 
Coastal Ecology Lab (VUCEL) and laboratory logistic support by the University of Melbourne. We gratefully acknowledge the research and technical assistance from the following people: V. Hernaman, C. McDermott, M. Forsyth, S. Geange, B. Dudley, L. Liggins, J. Allen, R. Williamson, J. Long, D. McNaughtan, and J. Ford. We thank 5 anonymous reviewers for constructive comments on an earlier draft.

\section{LITERATURE CITED}

Almany GR, Berumen ML, Thorrold SR, Planes S, Jones GP (2007) Local replenishment of coral reef fish populations in a marine reserve. Science 316:742-744

Ammann AJ (2004) SMURFs: standard monitoring units for the recruitment of temperate reef fishes. J Exp Mar Biol Ecol 299:135-154

Barbee NC, Swearer SE (2007) Characterizing natal source population signatures in the diadromous fish Galaxias maculatus, using embryonic otolith chemistry. Mar Ecol Prog Ser 343:273-282

Borges R, Ben-Hamadou R, Chícharo MA, Ré P, Gonçalves EJ (2007) Horizontal spatial and temporal distribution patterns of nearshore larval fish assemblages at a temperate rocky shore. Estuar Coast Shelf Sci 71:412-428

Caley MJ, Carr MH, Hixon MA, Hughes TP, Jones GP, Menge BA (1996) Recruitment and the local dynamics of open marine populations. Annu Rev Ecol Syst 27:477-500

Campana SE (1999) Chemistry and composition of fish otoliths: pathways, mechanisms and applications. Mar Ecol Prog Ser 188:263-297

> Campana SE, Smith SJ, Hurley PCF (1989) Drift-retention dichotomy for larval haddock (Melanogrammus aeglefinus) spawned on Browns Bank. Can J Fish Aquat Sci 46:93-102

Clements K (2003) Triplefins. In: Andrew N, Francis M (eds) The living reef: the ecology of New Zealand's rocky reefs. Craig Potton, Nelson, p 160-167

> Cowen RK, Sponaugle S (2009) Larval dispersal and marine population connectivity. Annu Rev Mar Sci 1:443-466

Cowen RK, Paris CB, Srinivasan A (2006) Scaling of connectivity in marine populations. Science 311:522-527

Eggins SM, Kinsley LPJ, Shelley JMG (1998) Deposition and element fractionation processes during atmospheric pressure laser sampling for analysis by ICP-MS. Appl Surf Sci 127-129:278-286

- Feary DA, Clements KD (2006) Habitat use by triplefin species (Tripterygiidae) on rocky reefs in New Zealand. J Fish Biol 69:1031-1046

Francis M (2001) Coastal fishes of New Zealand: an identification guide. Reed, Auckland

Gaines SD, Bertness MD (1992) Dispersal of juveniles and variable recruitment in sessile marine species. Nature 360: 579-580

Gardner JPA (2000) Where are the mussels on Cook Strait (New Zealand) shores? Low seston quality as a possible factor limiting multi-species distributions. Mar Ecol Prog Ser 194:123-132

Hamilton SL, Regetz J, Warner RR (2008) Postsettlement survival linked to larval life in a marine fish. Proc Natl Acad Sci USA 105:1561-1566

Helson JG, Pledger S, Gardner JPA (2007) Does differential particulate food supply explain the presence of mussels in Wellington Harbour (New Zealand) and their absence on neighbouring Cook Strait shores? Estuar Coast Shelf Sci 72:223-234

> Hickford MJH, Schiel DR (2003) Comparative dispersal of larvae from demersal versus pelagic spawning fishes.
Mar Ecol Prog Ser 252:255-271

Hjort J (1914) Fluctuations in the great fisheries of northern Europe viewed in light of biological research. Rapp P-V Réun Cons Perm Int Explor Mer 20:1-228

> Jones GP, Milicich MJ, Emslie MJ, Lunow C (1999) Selfrecruitment in a coral reef fish population. Nature 402: 802-804

Kingsford MJ (1988) The early life history of fish in coastal waters of northen New Zealand: a review. NZ J Mar Freshw Res 22:463-479

Kritzer JP, Sale PF (2004) Metapopulation ecology in the sea: from Levins' model to marine ecology and fisheries science. Fish Fish 5:131-140

- Leggett WC, Frank KT (2008) Paradigms in fisheries oceanography. Oceanogr Mar Biol Annu Rev 46:331-364

$>$ Leis JM (2006) Are larvae of demersal fishes plankton or nekton? Adv Mar Biol 51:57-141

Maxwell BE (1956) Hydrobiological observations for Wellington Harbour. Trans R Soc NZ 88:493-503

> McDermott CJ, Shima JS (2006) Ontogenetic shifts in microhabitat preference of the temperate reef fish Forsterygion lapillum: implications for population limitation. Mar Ecol Prog Ser 320:259-266

Patterson HM, Swearer SE (2007) Long-distance dispersal and local retention of larvae as mechanisms of recruitment in an island population of a coral reef fish. Austral Ecol 32: $122-130$

SAS Institute (1999) SAS/STAT user's guide, version 8. SAS Institute, Cary, NC

Shima JS, Swearer SE (2009a) Larval quality is shaped by matrix effects: implications for connectivity in a marine metapopulation. Ecology 90:1255-1267

Shima JS, Swearer SE (2009b) Spatially variable larval histories may shape recruitment rates of a temperate reef fish. Mar Ecol Prog Ser 394:223-229

> Shima JS, Swearer SE (2010) The legacy of dispersal: larval experience shapes persistence later in the life of a reef fish. J Anim Ecol doi:10.1111/j.1365-2656.2010.01733.x

> Shima JS, Noonburg EG, Phillips NE (2010) Life history and matrix heterogeneity interact to shape metapopulation connectivity in spatially structured environments. Ecology 91:1215-1224

Sinclair M (1988) Marine populations: an essay on population regulation and speciation. University of Washington Press, Seattle, WA

Swearer SE, Caselle J, Lea DW, Warner RR (1999) Larval retention and recruitment in an island population of a coral reef fish. Nature 402:799-802

Swearer SE, Shima JS, Helberg ME, Thorrold SR and others (2002) Evidence of self-recruitment in demersal marine populations. Bull Mar Sci 70:251-271

Thompson SM (1979) Ecological and behavioural factors influencing the distribution and abundance patterns of tripterygiid fishes with particular reference to Tripterygion varium. MSc thesis, University of Auckland

Thorrold SR, Swearer SE (2009) Otolith chemistry. In: Green BS, Begg GA, Carlos G, Mapstone, BD (eds) Tropical fish otoliths: information for assessment, management and ecology. Springer, Dordrecht, p 249-296

Thorson G (1950) Reproductive and larval biology of marine bottom invertebrates. Biol Rev Camb Philos Soc 25:1-45

- Wang X, Smith K, Hyndman R (2006) Characteristic-based clustering for time series data. Data Min Knowl Discov 13: 335-364

Wellenreuther M, Barrett PT, Clements KD (2007) Ecological diversification in habitat use by subtidal triplefin fishes (Tripterygiidae). Mar Ecol Prog Ser 330:235-246 